\title{
Vertical Blade Fiberglass Composite for Wind Turbine Power Plant Application
}

\author{
M. Abdus Shomad ${ }^{1 *}$, Fahmi Ruddin Hidayat $^{2}$ \\ ${ }^{1,2}$ D3 Mechanical Engineering Study Program, Vocational Program, Universitas Muhammadiyah Yogyakarta \\ Email: abdusshomad@umy.ac.id \\ *Corresponding Author
}

\begin{abstract}
Wind is a renewable energy that is used for electrical energy in several countries. Indonesia is one of the countries that utilizes wind energy for electrical energy. The potential for wind in Indonesia is located in coastal areas. To apply the potential for wind in urban areas is very difficult because the wind speed is very low. From this problem, this paper presents a windmill using fiberglass. Fiberglass is an alloy or mixture as a composite material which has the characteristics of light weight, easy shape, and low cost. The aim is to analyze the mechanical properties of fiberglass composite materials in the application of blades or vanes in savionus windmills. This study uses the hand lay-up method and the mechanical testing method for tensile strength and impact which aims to determine the material properties of the blade of the savonius windmill. Based on the tensile test, the average tensile strength of random fiberglass composite and 200gr 2-layer woven roving was 49.52 MPa with an average modulus of elasticity of $21.88 \mathrm{Gpa}$. For the Charphy impact test, the average impact strength is 0.035 joules $/ \mathrm{mm} 2$ with the energy absorbed is 0.7046 joules.
\end{abstract}

Keywords-Composite, Fiberglass, Savionus, Windmill

\section{INTRODUCTION}

Energy is a basic human need, which continues to increase in line with the level of life. Fuel oil (BBM) holds a very dominant position in meeting national energy needs. The composition of the current national energy consumption is BBM: 52.50\%; Gas: 19.04\%; Coal: 21.52\%; Water: 3.73\%; Geothermal: $3.01 \%$; and New Energy: 0.2\%. This condition occurred as a result of the past subsidy policies for fuel oil in an effort to spur the acceleration of economic growth. A fact that cannot be denied is that of oil production. Indonesia has experienced a decline due to a natural decline and the depletion of reserves. Several previous researchers have conducted research on energy problems. Energy Harvesting by Foot Using Piezoelectric Based on the LCT3588 Circuit and Boost up Converter was investigated by Iswanto [1]. Uninterrupted Power Supply based on Switching Regulator and Modified Sine Wave was investigated by Chamim [2]. Piezoelectric control of accumulator filling based on fuzzy scheduling was investigated by Iswanto [3]. The analysis and evaluation of the suitability of the use of cogeneration biogas plants was investigated by Sumarokova [4]. A Cost Comparison of the Energy Level Cost of a Superconducting Direct Drive Generator for a 10 MW Offshore Wind Turbine was investigated by Abrahamsen [5]. The Optimal Capacitive Energy Storage (CES) Design for Load Frequency Control in Micro Hydro Power Plants Using the Flower Pollination Algorithm was researched by Ali [6].
Wind energy is a renewable energy that is currently widely used in several countries that have wind potential. Indonesia itself is one of the countries that has the potential for winds with average speeds ranging from $3 \mathrm{~m} / \mathrm{s}$ to $5 \mathrm{~m} /$ s. Wind energy has been widely researched by previous researchers. The nonlinear dynamic power tracking of a low power wind energy conversion system was investigated by Yang [7]. Wide-Speed-Range-Operation Dual StatorWinding Induction Generator DC Generating System for Wind Power Applications was researched by $\mathrm{Bu}$ [8]. A market-oriented optimal delivery strategy for wind farms with multiple-stage hybrid energy storage systems was investigated by Zhang [9]. Coordinated Control of Wind Energy Conversion Systems for Mitigation of Subsynchronous Interactions in DFIG-based Wind Farms was investigated by Karaagac [10]. Statistical Characterization of Wind Power Ramps through Extreme Value Analysis was investigated by Ganger [11]. The optimization of a battery-supercapacitor hybrid energy storage station in a wind / solar power generation system was investigated by Zhou [12]. The analysis of the connection of local energy potential with a $10 \mathrm{~kW}$ archimedes turbine-based power plant was investigated by Apriani [13]. Continuous Power Flow and Time Domain Analysis to Assess Voltage Stability was investigated by Oktaviani [14].

Windmills are a device used in wind energy conversion systems (SKEA). Windmills function by converting wind kinetic energy into mechanical energy in the form of shaft rotation. Research on windmills has been carried out by previous researchers. Consideration of windmill modeling and factors affecting stability of wind-based embedded generators connected to the hotel grid by [15]. Efficient Piezoelectric Windmill Topology for Harvesting Energy from Low Speed Air Flow was investigated by [16]. The rotation of the shaft in the windmill is then used for several things according to needs, such as turning a dynamo or generator to produce electricity. The propeller or blade is an important part of a windmill because the blade acts as a cross section that functions as a reservoir for air flow which is made to produce lift and thrust at certain times which are used by the wind turbine. The weight of the blade affects the propulsion of wind energy. The heavier the blade, the very large wind energy required. The lighter the angle, it is affected by the strength of the blade to accommodate wind energy. The greater the wind energy, the lighter blades are easily broken. 
To overcome this problem, a lightweight, strong, weather-resistant material is needed. One of these materials is a composite material. Composites are materials that are composed of a mixture of two or more materials with different chemical and physical properties, and produce a new material that has different properties from the constituent materials. Fiberglass is one of the composites whose material is made of excellent fiber from glass. Fiberglass itself is used for production of insulation and textiles as well as as a material for plastics. Several previous researchers have conducted research on composite fiberglass. The non-contact RF characterization of the Reinforced Carbon Fiber Composite Material was investigated by Ciampalini. The RF method for characterization of carbon fiber reinforced with fiberglass was investigated [17]. Configurable Broadband Patch Antennas for Suitable Applications was researched by Wright. The proposed design considers structural fiberglass composites, Rohacell foam, structural epoxy, ultrathin graphite fiber, and conductive epoxy as materials of choice [18]. The Hexapod Robot Experimental Design and Development with a Fiberglass-Fibercarbon Composite Leg was investigated by Kebritchi. The design and control of a new RHex robot named IRHex with an innovative Fiberglass carbon fiber composite leg is described [19].

Characterization of Aircraft Radome Through Multiphysics Simulation was investigated by Whalen. A radome constructed using a composite fiberglass layer and foam core, and coated with an anti-static coating, paint, and primer was considered [20]. Bulk-based Superconductor Shielding and CC-Tape for Magnetic Cloaks researched by Solovyov. Two types of guiding inserts are used. The first type is a perforated cylinder made of a bulk superconducting material - BSCCO-2212. In the second type, there is a $12 \mathrm{~mm}$ wide conductor which is coated with a helix on the fiberglass which previously formed the protective layer [21]. The LogPeriodic-Dipole-Array (LPDA) near broadband structural composite material was investigated by Ali. The loading effect of structural composite materials on broadband LPDA is presented. The proposed antenna operates from 350-750 $\mathrm{MHz}$ and has a unique two-layer design in which the two antenna layers are detached on two separate fiberglass composite shell surfaces [22].

The trend plot for compound selection used for the MUF FCCSP warpage design with 4L ETS was investigated by Chen. Most substrates are composite structures of a dielectric layer reinforced with epoxy based fiberglass bonded with copper paper used to conduct electric current (power and ground plane) [23]. The theory of effective media for dry powder printing was researched by Good. Fiberglass composites with three dimensional various dielectric properties have been fabricated using a new dry powder dot deposition system. Out of field and the effective nature of the previous field are determined empirically by separate methods [24]. The electromagnetic characterization and validation of aircraft composite materials were investigated by da Silva. The electromagnetic characterization of typical composite materials found in aircraft structural parts using a method based on S-parameters that is not calibrated. Dielectric constants 4.60 and 1.84 and tangent losses of 2.0x10-2 and 6.1 $\times 10-2$ were obtained for fiberglass and honeycomb composite materials, respectively [25].

Accurate One-Sided Microwave Thickness Evaluation for Lined Fiberglass Composites was investigated by Ghasr. Fiberglass is increasingly being used for corrosion-resistant industrial applications. Fiberglass laminates usually consist of a structural layer and a corrosion-resistant layer (commonly referred to as a liner) on the inside of the laminate [26]. DC inclined plane tracking and erosion tests and the role of inorganic fillers in silicon rubber for DC insulation were investigated by Ghunem. The first polymer insulators for AC transmission lines were developed in the late 1950's. The isolator consists of a flexible epoxy resin fixed to a fiberglass rod, and field trials on 138-kV lines took place in 1959 [27]. Intelligent Thermal Control Welding Resistance Fiberglass Laminates for Auto Manufacturing researched by Zammar. A novel approach to automating large-scale resistance welding of thermoplastic composite materials, based on real-time temperature control, is presented in this paper. Resistance welding, a kind of fusion bonding, is a broad alternative process for mechanical bonding and adhesive bonding in joining with thermoplastic composites [28].

This paper is different from the papers mentioned above. In previous research, composite fiberaglass was used to coat the fuselage, to make robot leg legs, and to make antennas. Paper presented the use of fiberglass composites used to make blades in wind turbines. This paper aims to perform a composite test applied to a wind turbine blade using impact testing and tensile testing. Using this impact test aims to find out how much energy the material can absorb until the material is broken and this tensile test is to determine the strength of the material against the tensile load.

\section{RESEARCH METHODS}

In the manufacture of windmill blades, the method used is the hand lay-up of this method because it is cheaper, requires less equipment, adjusts thickness, and is easy to adjust the fiber composition The design drawing of the blade of the savionus windmill is shown in Figure 1. From this figure, it can be seen that the height of the blade of the savionus windmill is $72 \mathrm{~cm}$.

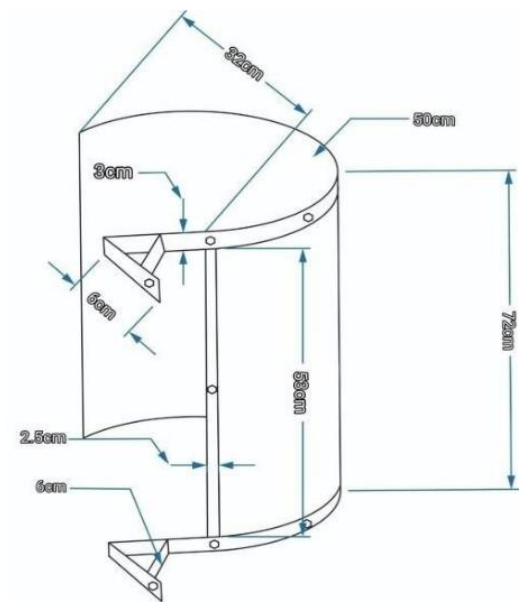

Fig. 1. Design drawing of the savionus windmill blade

Then the test method is to test the tensile strength and impact values. Where the tensile test aims to determine the 
ability of a material when receiving a tensile load and impact testing to determine the resistance of a material when receiving a shock load. With variations in specimen making, namely 2 layers of random fiber, 2 layers of wr200 2 layers of random fiber and 2 layers of WR200. Then the specimens were formed according to the ASTM D 638 tensile test standard and the ASTM D 5942-96 impact test standard. The matrix material used is the polyester type, which is clear polyester 108 . Then after the specimen is finished, tensile testing and impact testing are carried out. Where the tensile test aims to determine the ability of a material when receiving tensile loads and impact testing to determine the resistance of a material when receiving a shock load.

\section{PREPARE YOUR PAPER BEFORE STYLING}

After the manufacturing process is carried out by hand lay-up, the tensile strength and impact test are then carried out

\section{Results of Tensile Testing and Impact Testing}

\section{Tensile Testing Results}

The results of the tensile test are shown in table 1, namely the table of the Average Tensile Strength of the Specimen. The table shows that there are three variations in the Tensile strength test and the modulus of elasticity test. The 2-layer random variation resulted in a tensile test of $43.08 \mathrm{Mpa}$ and a modulus of elasticity of $17.39 \mathrm{Gpa}$. Variation WR200 2 layers resulted in a tensile test of $55.98 \mathrm{MPa}$ and a modulus of elasticity of $24.81 \mathrm{Gpa}$. The random variation of the 2layer WR200 resulted in a tensile test of $49.52 \mathrm{MPa}$ and a modulus of elasticity of $21.88 \mathrm{Gpa}$.

TABLE I. Results of Average Tensile Strength of SPecimens

\begin{tabular}{|c|c|c|}
\hline Variation & $\begin{array}{c}\text { Tensile strength } \\
(\mathrm{Mpa})\end{array}$ & $\begin{array}{c}\text { Modulus of } \\
\text { Elasticity (Gpa) }\end{array}$ \\
\hline Random 2 layers & 43.08 & 17.39 \\
\hline WR200 2 layers & 55.98 & 24.81 \\
\hline Random 2 WR200 & 49.52 & 21.88 \\
\hline
\end{tabular}

The Average Tensile Strength Graph is shown in Figure 2 and the Average Modulus of Elasticity Graph shown in Figure 3 is made from data table 1 .

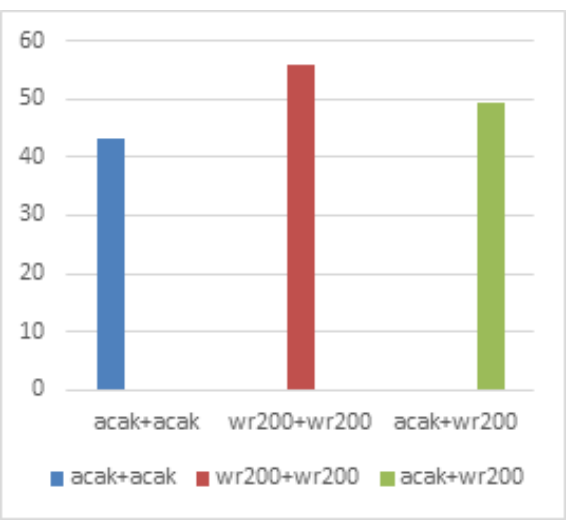

Fig. 2. Design drawing of the savionus windmill blade
Graph of Average Tensile Strength is shown in Figure 2. From this figure, it can be seen that there are three experiments on average tensile strength. The average tensile strength that has a high value in the variation of wr200+ wr200 with a value of 55.98 is shown on the red curve. Average Tensile Strength having a low value on random + random variation with a value of 43.08 shown on the blue curve. The random variation + wr200 has an average tensile strength value of 49.52

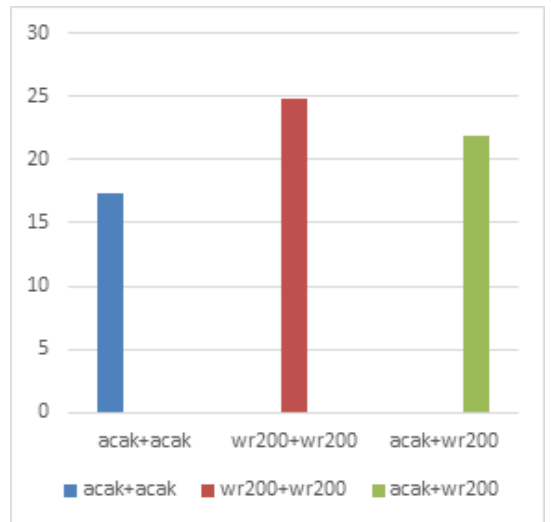

Fig. 3. Average Modulus of Elasticity Graph

The graph of the Average Modulus of Elasticity is shown in Figure 3.From this figure, it can be seen that there are three experiments on the average tensile strength. The average tensile strength that has a high value in the variation of wr200 + wr200 with a value of 24.81 is shown in the red curve. Average Tensile Strength having a low value on random + random variation with a value of 17.39 shown on the blue curve. The random variation + wr200 has an average tensile strength value of 21.88

\section{Impact Testing Results}

The results of the impact test are shown in table 2, namely the table of Average Impact Strengths. From the table it is shown that there are three variations in the Absorbed Energy test and the Impact Strength test. The 2-layer random variation produces an Absorbed Energy of $0.6233 \mathrm{~J}$ and an Impact Strength test of $0.023 \mathrm{~J} / \mathrm{mm}$. The 2-layer WR200 variation results in an Absorbed Energy test of $0.7588 \mathrm{~J}$ and an Impact Strength test of $0.035 \mathrm{~J} / \mathrm{mm}$. Random variations of the 2-layer WR200 resulted in an Absorbed Energy test of $0.7046 \mathrm{~J}$ and an Impact Strength test of $0.035 \mathrm{~J} / \mathrm{mm}$.

TABLE II. Results OF AVERAge TENSILE STRENGTH OF SPECIMENS

\begin{tabular}{|c|c|c|}
\hline Variation & $\begin{array}{c}\text { Energy Absorbed } \\
(\mathrm{J})\end{array}$ & $\begin{array}{c}\text { Impact Strength } \\
(\mathrm{J} / \mathrm{mm} 2)\end{array}$ \\
\hline Random 2 layers & 0.6233 & 0.023 \\
\hline WR200 2 layers & 0.7588 & 0.035 \\
\hline Random WR200 2 & 0.7046 & 0.035 \\
\hline
\end{tabular}

The Graph of Average Absorbed Energy is shown in figure 4 and the Graph of Average Impact Strength is shown in figure 5 made from data table 2. 


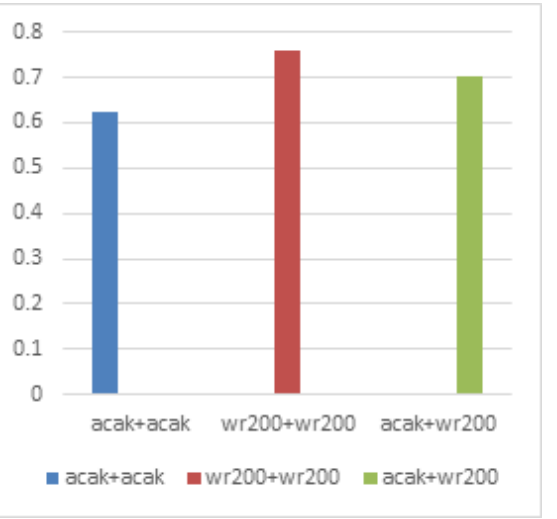

Fig. 4. Graph of Average Energy Absorbed

Graph of Average Absorbed Energy is shown in Figure 4. From this figure it can be seen that there are three experiments on Average Energy Absorbed. Energy Absorbed Average which has a high value in the variation of wr200+ wr200 with a value of 0.7588 which is shown in the red curve. Average Absorbed Energy which has a low value on random + random variation with a value of 0.6233 shown on the blue curve. The random variation + wr200 has an Average Absorbed Energy value of 0.7046

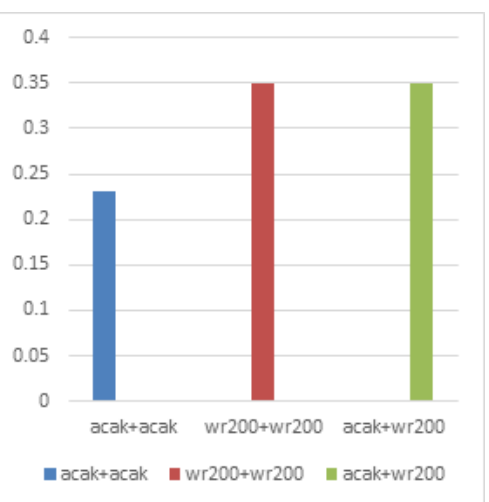

Fig. 5. Average Impact Strength Graph

The graph of the Average Impact Strength is shown in Figure 5. From this figure it can be seen that there are three experiments on the Average Impact Strength. High Average Impact Strength on the 2 layer WR200 variation and the 2 layer Random WR200 with a value of 0.035 shown on the red and green color curves. Average Absorbed Energy which has a low value on random + random variation with a value of 0.023 shown on the blue curve.

From the random fiber tensile test and 200gr 2-layer woven roving, the results are in accordance with estimates where the average tensile strength is $49.52 \mathrm{MPa}$ with a modulus of elasticity of $21.88 \mathrm{Gpa}$ these results are in the middle where the average tensile strength of the fiber woven roving 200gr 2 layers of $55.98 \mathrm{Mpa}$ with a modulus of elasticity of $24.81 \mathrm{Gpa}$, while for random fiber 2 layers the average tensile strength is $43.08 \mathrm{MPa}$ with a modulus of elasticity of $17.39 \mathrm{Gpa}$, this value is obtained from the hand method. -lay up where the number of voids that affect the tensile strength and impact on the specimen under test. Likewise in the impact test the strength produced by random fibers and $200 \mathrm{gr}$ woven roving fibers has a strength value that is in the middle between 2-layer random fiberglass and 2- layer woven roving with an absorbed energy of 0.7046 joules and an impact strength of 0.035 joules $/ \mathrm{mm} 2$.

From the tests that have been done, it was found that the use of a composite with 200gr 2-layer woven roving fiber reinforcement has the highest tensile strength when compared to the other 2 variations because the shape of the woven roving fiber is a straight and long woven fiber so that the strength is along the length of the fiber, then to 2 layers of random fibers get the tensile strength results under both variations of the test, this is because random fibers are short fibers arranged to form a sheet so that the strength is only along the short fiber, while for random fibers and $200 \mathrm{gr}$ woven roving 2 layers the strength is in the middle between 2 layers of random fiber and $200 \mathrm{gr} 2$ layers of woven roving is due to the large role of $200 \mathrm{gr}$ woven roving fibers in resisting greater tensile forces so that the tensile strength results are above 2 layers of random fibers but still under 2 layers of $200 \mathrm{gr}$ woven roving fibers, this also applies to impact testing.

\section{USING THE TEMPLATE}

Based on the results of making savonius windmill blade products and analysis of the testing and discussion of the data obtained, it can be concluded as follows: Making savonius windmill blades using the hand layup method and resulting savonius blades consisting of 2 layers, namely: the first layer using fiber random second layer using 200 gr woven roving fiber. Based on the results of the tensile test, the average tensile strength of the composite on 2 layers of random fibers is $43.08 \mathrm{MPa}$, for $200 \mathrm{gr}$ woven roving fibers 2 layers the average tensile strength of the composite is $55.98 \mathrm{MPa}$, while for random fibers and woven roving $200 \mathrm{gr}$ the strength the average tensile strength of the composite was $49.52 \mathrm{Mpa}$. Based on the results of the impact test, the average impact strength of the composite on random fibers is 0.023 joules / $\mathrm{mm} 2$ with an average energy absorbed of 0.6233 joules, for $200 \mathrm{gr}$ woven roving fibers the average impact strength is 0.035 joules / $\mathrm{mm} 2$ with absorbed energy. amounting to 0.7588 joules, while for random fibers and $200 \mathrm{gr}$ woven roving 2 layers the resulting impact strength is 0.035 joules / $\mathrm{mm} 2$ with the energy absorbed is 0.7046 joules. The type of fiberglass fiber affects the characteristics of composites such as 2-layer $200 \mathrm{gr}$ woven roving fiberglass fiber which has the highest modulus of elasticity when compared to 2-layer random fiber, 200gr woven roving and 2-layer random fiber, then random fiber and 200gr 2-layer woven roving fibers have a more modulus of elasticity. 2 layers of $200 \mathrm{gr}$ woven roving but higher than 2-layer random, whereas 2-layer random fiber has the lowest modulus of elasticity of the two.

\section{REFERENCES}

[1] Iswanto, S. Suripto, F. Mujahid, K. T. Putra, N. P. Apriyanto, and Y. Apriani, "Energy Harvesting on Footsteps Using Piezoelectric based on Circuit LCT3588 and Boost up Converter,' Int. J. Electr. Comput. Eng., vol. 8, no. 6, pp. 4104-4110, 2018.

[2] A. N. N. Chamim, M. Heru Gustaman, N. M. Raharja, and I. Iswanto, "Uninterruptable Power Supply based on Switching Regulator and Modified Sine Wave," Int. J. Electr. Comput. Eng., vol. 7, no. 3, p. 1161, Jun. 2017.

[3] I. Iswanto, W. S. Agustiningsih, F. Mujaahid, R. Rohmansyah, and A. Budiman, "Accumulator Charging Control with Piezoelectric Based on 
Fuzzy Algorithm Scheduling," TELKOMNIKA (Telecommunication Comput. Electron. Control., vol. 16, no. 2, p. 635, Apr. 2018.

[4] L. P. Sumarokova and V. A. Ershov, "Analysis and evaluation of the appropriateness of the use of cogeneration biogas plants," in 2016 2nd International Conference on Industrial Engineering, Applications and Manufacturing (ICIEAM), 2016, pp. 1-6.

[5] A. B. Abrahamsen et al., "Comparison of Levelized Cost of Energy of Superconducting Direct Drive Generators for a 10-MW Offshore Wind Turbine," IEEE Trans. Appl. Supercond., vol. 28, no. 4, pp. 1-5, Jun. 2018.

[6] M. Ali, M. R. Djalal, M. Fakhrurozi, Kadaryono, Budiman, and D. Ajiatmo, "Optimal Design Capacitive Energy Storage (CES) for Load Frequency Control in Micro Hydro Power Plant Using Flower Pollination Algorithm," in 2018 Electrical Power, Electronics, Communications, Controls and Informatics Seminar (EECCIS), 2018, pp. 21-26.

[7] Y. Yang, K.-T. Mok, S.-C. Tan, and S. Y. R. Hui, "Nonlinear dynamic power tracking of low-power wind energy conversion system," IEEE Trans. Power Electron., vol. 30, no. 9, pp. 5223-5236, Sep. 2015.

[8] F. Bu, Y. Hu, W. Huang, S. Zhuang, and K. Shi, "Wide-Speed-RangeOperation Dual Stator-Winding Induction Generator DC Generating System for Wind Power Applications," IEEE Trans. Power Electron., vol. 30, no. 2, pp. 561-573, Feb. 2015.

[9] Z. Zhang, Y. Zhang, Q. Huang, and W.-J. Lee, "Market-oriented optimal dispatching strategy for a wind farm with a multiple stage hybrid energy storage system," CSEE J. Power Energy Syst., vol. 4, no. 4, pp. 417-424, Dec. 2018.

[10] U. Karaagac, S. O. Faried, J. Mahseredjian, and A.-A. Edris, "Coordinated Control of Wind Energy Conversion Systems for Mitigating Subsynchronous Interaction in DFIG-Based Wind Farms," IEEE Trans. Smart Grid, vol. 5, no. 5, pp. 2440-2449, Sep. 2014.

[11] D. Ganger, J. Zhang, and V. Vittal, "Statistical Characterization of Wind Power Ramps Via Extreme Value Analysis," IEEE Trans. Power Syst., vol. 29, no. 6, pp. 3118-3119, Nov. 2014.

[12] T. Zhou and W. Sun, "Optimization of Battery-Supercapacitor Hybrid Energy Storage Station in Wind/Solar Generation System," IEEE Trans. Sustain. Energy, vol. 5, no. 2, pp. 408-415, Apr. 2014.

[13] Y. Apriani, Z. Saleh, R. K. Dillah, and I. M. Sofian, "Analysis of the local energy potential connection with power plants based on archimedes turbine 10 kW," J. Robot. Control, vol. 1, no. 5, pp. 162$166,2020$.

[14] W. A. Oktaviani, T. Barlian, Y. Apriani, and N. Syarif, "Continuous Power Flow and Time Domain Analysis for Assessing Voltage Stability," J. Robot. Control, vol. 1, no. 6, pp. 191-198, 2020.

[15] S. K. Salman and A. L. J. Teo, "Windmill modeling consideration and factors influencing the stability of a grid-connected wind power-based embedded generator," IEEE Trans. Power Syst., vol. 18, no. 2, pp. 793802, May 2003.

[16] N. Rezaei, A. Tabesh, R. Dehghani, and A. Aghili, "An Efficient Piezoelectric Windmill Topology for Energy Harvesting from Low
Speed Air Flows," IEEE Trans. Ind. Electron., vol. 62, no. 6, pp. 1-1, 2014.

[17] C. Ciampalini, P. Usai, G. Nenna, F. Costa, and A. Monorchio, "Noncontact RF Characterization of Reinforced Carbon Fiber Composite Materials," in 2018 IEEE International Symposium on Antennas and Propagation \& USNC/URSI National Radio Science Meeting, 2018, pp. 1065-1066.

[18] M. D. Wright, W. Baron, J. Miller, J. Tuss, D. Zeppettella, and M. Ali, "MEMS Reconfigurable Broadband Patch Antenna for Conformal Applications," IEEE Trans. Antennas Propag., vol. 66, no. 6, pp. 27702778, Jun. 2018.

[19] A. Kebritchi, S. Havashinezhadian, and M. Rostami, "Design and Experimental Development of Hexapod Robot with FiberglassFibercarbon Composite Legs," in 2018 6th RSI International Conference on Robotics and Mechatronics (IcRoM), 2018, no. IcRoM, pp. 439-444.

[20] E. Whalen, G. Gampala, K. Hunter, S. Mishra, and C. J. Reddy, "Aircraft Radome Characterization via Multiphysics Simulation," in 2018 AMTA Proceedings, 2018, pp. 1-4.

[21] M. Solovyov et al., "Bulk and CC-Tape Based Superconducting Shields for Magnetic Cloaks," IEEE Trans. Appl. Supercond., vol. 27, no. 4, pp. 1-4, Jun. 2017.

[22] M. Ali, N. A. Bishop, W. Baron, J. Miller, J. Tuss, and D. Zeppettella, "Structural composite materials near a broadband Log-PeriodicDipole-Array (LPDA)," in 2017 IEEE International Symposium on Antennas and Propagation \& USNC/URSI National Radio Science Meeting, 2017, pp. 1547-1548.

[23] C. Chen, N. Kao, and D. S. Jiang, "Trend plots for compound selection utilized for warpage design of MUF FCCSP with 4L ETS," in 2017 IEEE 19th Electronics Packaging Technology Conference (EPTC), 2017, no. 153 , pp. 1-10.

[24] B. L. Good, D. A. Roper, M. S. Mirotznik, and A. J. Good, "Effective media theory of dry powder dot printing," in 2016 IEEE International Symposium on Antennas and Propagation (APSURSI), 2016, pp. 1987-1988.

[25] L. G. da Silva et al., "Electromagnetic characterization and validation of aircraft composite materials," in 2016 10th European Conference on Antennas and Propagation (EuCAP), 2016, pp. 1-5.

[26] M. T. Ghasr, M. J. Horst, M. Lechuga, R. Rapoza, C. J. Renoud, and R. Zoughi, "Accurate One-Sided Microwave Thickness Evaluation of Lined-Fiberglass Composites," IEEE Trans. Instrum. Meas., vol. 64, no. 10 , pp. 2802-2812, Oct. 2015.

[27] R. Ghunem, S. Jayaram, and E. Cherney, "The DC inclined-plane tracking and erosion test and the role of inorganic fillers in silicone rubber for DC insulation," IEEE Electr. Insul. Mag., vol. 31, no. 1, pp. 12-21, Jan. 2015.

[28] I. A. Zammar, I. Mantegh, M. S. Huq, A. Yousefpour, and M. Ahmadi, "Intelligent Thermal Control of Resistance Welding of Fiberglass Laminates for Automated Manufacturing," IEEE/ASME Trans. Mechatronics, vol. 20, no. 3, pp. 1069-1078, Jun. 2015.. 